\title{
Portal MOM - Morar de outras maneiras: inconsistências em design de interface
}

Portal MOM - Living in other ways: inconsistencies in interface design

\author{
LIMA, Julyana; Mestranda em Design; UFMA \\ julyana.slima.jl@gmail.com \\ MUNIZ, Raissa; Mestranda em Design; UFMA \\ raissamunizpinto@gmail.com \\ MONT'ALVÃO, Claúdia; Professora Doutora; PUC-Rio \\ claudiarbr@gmail.com \\ SANTOS, Denilson; Professor Doutor; UFMA \\ denilson.santos@ufma.br \\ DINIZ, Raimundo; Professor Doutor; UFMA \\ rl.diniz@ufma.br
}

\section{Resumo}

Os sites de departamentos acadêmicos, grupos de pesquisa e outros programas universitários, em sua grande maioria, apontam significativas falhas na relação de interação humano-computador. 0 artigo tem como objetivo identificar e expor as inconsistências presentes na página virtual do grupo de pesquisa denominado MOM - Morar de outras maneiras, sediado pelo Departamento de Projetos (PRJ) e pelo Programa de Pós-graduação em Arquitetura e Urbanismo (NPGAU) da Escola de Arquitetura da UFMG. A partir do método de avaliação empírica Protocolo Verbal realizado com estudantes pesquisadores da área da arquitetura, foi possível verificar as reais dificuldades de usabilidade com o site escolhido como objeto de estudo. Verificou-se a necessidade de projetar interfaces sob a ótica do usuário, demonstrando os impasses da justaposição da originalidade à usabilidade.

Palavras Chave: interface digital; protocolo verbal; usabilidade e avaliação empírica.

\begin{abstract}
Academic departmental sites, research groups, and other university programs, for the most part, point to significant flaws in the human-computer interaction relationship. The article aims to identify and expose the inconsistencies present in the virtual page of the research group called MOM - Living in other ways, hosted by the Department of Projects (PRJ) and the Postgraduate Program in Architecture and Urbanism (NPGAU) of Architecture of UFMG. From the empirical method Verbal Protocol conducted with users students and researchers in the area of Architecture, it was possible to verify the real difficulties of usability with the site chosen as object of study.
\end{abstract}

Keywords: digital interface; verbal protocol; usability and empirical evaluation. 


\section{Introdução}

A noção de que o design deve ser centrado no usuário vem ganhando espaço no campo das interfaces digitais. Considerando o designer como solucionador de problemas reais, o profissional deve ser um facilitador de experiências entre o usuário e o mundo, inclusive no meio digital. Desse modo, simplificar os projetos de interfaces, em uma era de excesso de informações, promove experiências mais agradáveis aos usuários.

Para centrar o projeto no usuário, é necessário incluí-lo no processo de desenvolvimento de interfaces de tal forma que não apenas o cliente/contratante e o projetista discutam os resultados do projeto. A busca por satisfação do usuário em interfaces digitais é relevante e consiste em um desafio para desenvolvedores de sistemas do tipo sites. Segundo Lowdermilk (2013), o design centrado no usuário é uma metodologia derivada da Interação Humano-Computador (IHC), cujo foco está totalmente na experiência de usuário. Assim, é imprescindível uma análise mais apurada acerca das necessidades do usuário, do contexto de uso do dispositivo e do comportamento humano.

Entretanto, nota-se aspectos contrários as ideias de usabilidade em diversos sites e aplicativos no meio digital, com desenvolvimento de pesquisas na área ocorrendo dentro da academia e no mercado (MEMORIA \& MONT'ALVÃO, 2004). Todavia, ambas são voltadas para o mercado, ou seja, sites de ampla circulação. Isto, podendo ser verificado entre os periódicos CAPES no ano de 2017, o foco em pesquisas de usabilidade voltadas a fidelização de clientes em sites e à acessibilidade para pessoas com deficiência. No entanto, uma parcela de sites que aparece ainda timidamente nas pesquisas refere-se justamente ao meio acadêmico. Sites de universidades, grupos de pesquisa e afins, onde apesar do grau de instrução maior que grande parcela da sociedade, muitos usuários (graduandos, pesquisadores e professores) com experiências semelhantes em sistemas de interfaces digitais também se deparam com dificuldades de interação durante a utilização destes.

Desse modo, o artigo explana a página virtual do grupo de pesquisa denominado MOM Morar de Outras Maneiras, sediado pelo Departamento de Projetos (PRJ) e pelo Programa de Pósgraduação em Arquitetura e Urbanismo (NPGAU) da Escola de Arquitetura da UFMG. O grupo MOM busca investigar processos de produção de moradias, do seu ambiente urbano e de outros espaços cotidianos, com perspectivas de autonomia dos moradores, construtores diretos e grupos primários, economia social e processos construtivos de impacto ambiental controlado. Os estudos deste grupo de pesquisa visam um determinado público: as pessoas que produzem suas moradias informalmente devido à escassez de recursos financeiros, técnicos e jurídicos; ou as pessoas que se submetem a empreendimentos formais nos quais têm pouco poder de decisão.

A partir da realidade que busca estudar, o Grupo MOM torna-se de grande relevância para pesquisadores maranhenses, na medida em que o estado apresenta um déficit evidente na moradia, representada em centenas de bairros periféricos nas cidades, além de povoados rurais espalhados pelo estado. Tais moradias são caracterizadas como "domicílios carentes", segundo o IBGE, que revela a taxa de $98 \%$ de deficiência habitacional em 114 municípios, que comparece também na inadequação construtiva das habitações, coabitação ou quantidade excessiva de moradores. Além de representar o segundo grupo de estudos do MOM, com programas governamentais que produzem moradias com escassas dimensões físicas incapazes de atender critérios prescritos de higiene e conforto. 
Como forma de modificar esta realidade no estado, o Grupo MOM comparece como importante fonte de informações, podendo ser assim caracterizados os principais usuários do site: estudantes, pesquisadores e professores da área de Arquitetura e Urbanismo, principalmente de fora do próprio grupo que usam o site como referências para suas publicações.

Ademais, o site em questão atua como um facilitador para a navegação e conhecimento das atividades acadêmicas ao se interligar com vários outros projetos da instituição, muitas vezes desconhecidos dos próprios alunos. Por isso, é importante que o site esteja coerente às necessidades imediatas dos usuários.

Por conseguinte, o objetivo deste artigo é apresentar as dificuldades e as inconsistências encontradas por usuários ao interagir com o site escolhido, além de estabelecer o grau de satisfação desses usuários, visando colaborar com a melhoria futura do sistema e enfatizando a necessidade de desenvolver interfaces com as considerações dos usuários. Vale ressaltar que a pesquisa não visa a proposição de prototipagem do site a partir dos resultados obtidos. Com o intuito de demarcar a necessidade de melhoria para o site e futuramente produzir um sistema com interface mais intuitiva, seleciona-se o protocolo verbal como método de avaliação empírica para testar e avaliar a interface. Tal metodologia é aplicada em ambiente universitário com alunos pesquisadores da área de Arquitetura e Urbanismo.

A seguir, o artigo discorre em outras cinco seções. A primeira seção traz uma breve fundamentação da interação do homem-computador no contexto dos sites acadêmicos. Em seguida, a segunda seção aprofunda-se no método escolhido para a análise do site escolhido como objeto de estudo, abordando o método empírico e a ferramenta específica protocolo verbal. Partindo para a etapa prática, a terceira seção apresenta os passos metodológicos para análise do site do grupo MOM bem como a aplicação dos mesmos. Dando prosseguimento, são explanados os resultados e o a última seção demonstra a discussão dos dados finais obtidos na pesquisa.

\section{Interação Humano-Computador em Portais}

A sociedade pós-moderna vivencia um processo de profundas transformações, onde as tecnologias constituem-se como responsáveis principais. A era atual é caracterizada pela elevada produção e disseminação de conhecimento, de tal modo que alguns autores já consideram o surgimento de um novo paradigma da sociedade e denominam como Sociedade da Informação (SILVA \& SERAFIM, 2016). Através da internet, as informações são veiculadas de forma instantânea para qualquer lugar do mundo. Essa realidade acarretou o surgimento de milhões de sítios eletrônicos ou portais (em inglês, websites ou sites) de forma a atender diversas áreas, tais como educação, negócios, governo e saúde.

São classificados como portais as páginas na Internet que servem como ponto de acesso direto a um conjunto de informações e serviços (MORE et al, 2010). O objetivo principal dos sites também denominado portais - é o acesso imediato a um conjunto de informações, dados e serviços pelo usuário, variando conforme o contexto de utilização, isto é, grupo de usuários atendidos ou pretendidos: públicos (público em geral) ou corporativos (público de uma empresa ou instituição). Assim, o meio acadêmico também se apropriou desta ferramenta, onde discentes, docentes e pesquisadores acessam as informações e serviços relevantes às atividades realizadas na instituição de forma mais centralizada (BITTENCOURT; DIAS, 2011). 
As universidades ancoram-se nos sites para uma gama diversificada de tarefas, sobrecarregando as ferramentas sem as atualizações necessárias. Vale lembrar também que são poucos os sites acadêmicos que atendem satisfatoriamente às necessidades dos usuários. Este panorama alerta para uma emergencial avaliação de usabilidade dos sistemas para identificar problemas e propor mudanças positivas.

O termo usabilidade consiste na avaliação para proposição de formas adequadas de interação dos usuários, desenvolvendo um sistema que alcance os objetivos finais. Assim, busca-se facilitar a vida do usuário tanto na percepção quanto na utilização dos recursos disponíveis pelos sistemas (FONSECA, 2004). A usabilidade em sites tornou-se crucial para o projeto e avaliação de site, visto que a difícil aprendizagem e utilização de um site pode ocasionar o abandono dos usuários (NIELSEN, 2012). Nielsen (2012) define usabilidade baseado nas dimensões abaixo e conforme a Figura 1:

- Facilidade de Aprendizado: Trata-se da facilidade de realizar tarefas básicas, pelo usuário, na primeira vez de uso.

- Eficiência: Refere-se à rapidez com que as tarefas podem ser realizadas, uma vez que os usuários aprenderam o site.

- Facilidade de Memorização: É a facilidade de proficiência quando os usuários retornam à interface após um período sem usá-lo.

- Erros: Sobre a quantidade de erros que os usuários cometem durante o uso, o nível de gravidades dos mesmo e a facilidade de recuperação dos mesmos.

- Satisfação: O nível de satisfação do usuário ao utilizar a interface ou ausência de desconforto.

Figura 1 - Dimensões da Usabilidade

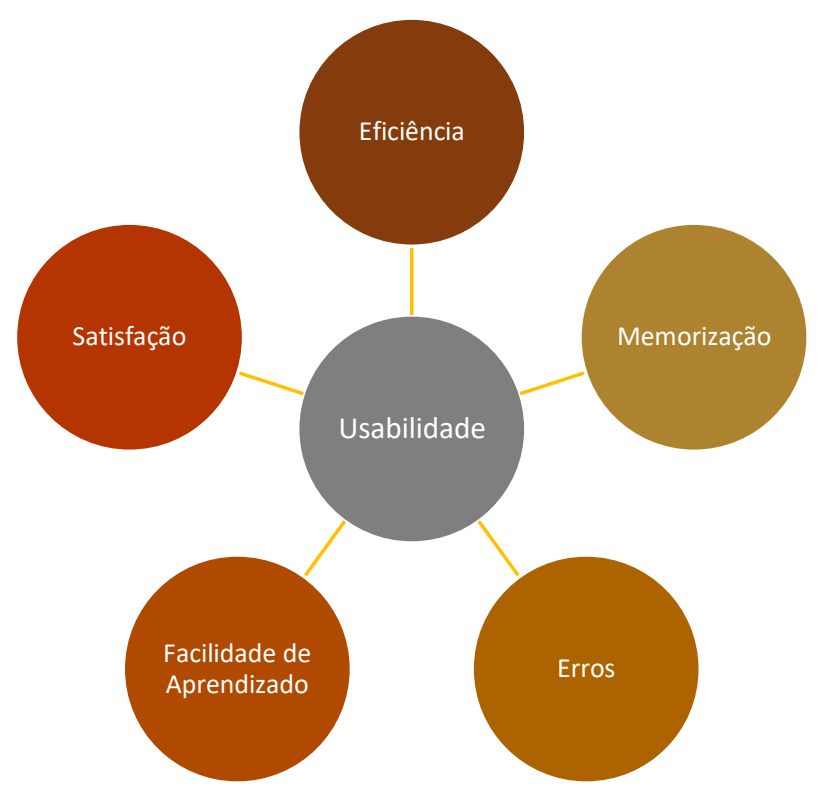

Fonte: Adaptado de NIELSEN (2012) 
Para o autor, uma interface deve conter tanto a usabilidade (recursos fáceis e agradáveis) quanto a utilidade (fornecer os recursos que o usuário precisa), visto que é incoerente um sistema que seja fácil, mas que não permite ao usuário fazer o que deseja.

A Interação Humano-Computador (IHC) é uma disciplina que aborda a usabilidade no quesito qualidade e percepção da informação. Segundo Prates \& Barbosa (2003), a IHC explora justamente os estudos relacionados ao projeto de construção de interfaces com alta qualidade. Logo, trata-se de uma disciplina intrínseca e necessária aos sites. Além disso, engloba também os estudos referentes à avaliação, buscando avaliar a qualidade de um projeto de interface ao longo do processo de desenvolvimento e quando o software está pronto. Para isto, são definidos métodos, modelos e diretrizes por diversos autores da área.

De forma geral, a Interação Humano-Computador é responsável pelo design (projeto), avaliação e implementação de sistemas interativos juntamente com os fenômenos associados ao uso humano (BARANAUSKAS; ROCHA, 2003). Preece (2005) conceitua avaliação como um processo sistemático de coleta de dados a fim de informar o modo como os usuários devem utilizar um produto/serviço para executar uma tarefa em determinado ambiente. A avaliação, portanto, é um importante instrumento de verificação das necessidades dos usuários para alcançar uma experiência exemplar.

Assim, a avaliação torna-se parte crucial da metodologia desta pesquisa. Neste artigo, dentre as atribuições do IHC, apenas o aspecto da avaliação será articulado, visto que o objeto de estudo é um sistema já construído. A seguir, é abordada algumas importantes considerações do método de avaliação empírica a ser aplicado na pesquisa em questão.

\section{Método de Pesquisa}

O método de avaliação empírica, de forma geral, envolve usuários para a coleta de dados, que são posteriormente analisados pelo especialista para identificar os problemas da interface. Aborda-se aqui uma ferramenta aplicável de forma eficiente em métodos de avaliação de interfaces realizados em ambientes controlados.

Uma das maiores vantagens de testes com usuários em laboratórios diz respeito ao controle maior do avaliador tanto sobre o ambiente quanto sobre as atividades do usuário. Neste contexto, o avaliador é capaz de identificar problemas da interface que dificultam a interação, porém sem a preocupação com fatores externos, tais como problemas nos dispositivos, falhas na conexão ou interrupções durante o uso do sistema. A desvantagem principal de tais testes em laboratórios consiste na realização da avaliação fora do contexto em que a aplicação seria utilizada de fato, ou seja, não é possível fatores do ambiente externo que podem impactar durante o manuseio do sistema (PRATES; BARBOSA, 2003).

Existem diversos métodos que proporcionam uma avaliação de um sistema com usuário no laboratório. O Protocolo Verbal, também conhecido por Verbalização, Think Aloud e "Pensar Alto", é uma técnica que funciona através da observação da interação e da interpretação das ponderações expressas verbalmente pelos usuários, viabilizando a identificação de problemas de usabilidade enfrentados em situações reais.

A técnica é constantemente empregada como instrumento de pesquisa em coletas de dados 
por diversas áreas do conhecimento, principalmente pelo design, educação e psicologia. Tais coletas fornecem informações relevantes sobre os processos mentais dos usuários que estão executando as tarefas (FUJITA, 2009). Segundo Mattos et al. (2017), o Protocolo Verbal é um método de investigação que apresenta resultados satisfatórios no campo das Ciências Humanas, isto é, em estudos comportamentais em que seja necessário concluir mecanismos ou processos cognitivos através de verbalizações.

Neste método, existem duas técnicas de verbalização aplicáveis: a concorrente e a retrospectiva. A diferença entre ambas se dá na intensidade da introspecção empregada durante o desenvolvimento de uma tarefa. Em outras palavras, a técnica concorrente consiste na verbalização simultânea à realização de uma determinada tarefa, enquanto a retrospectiva solicita a verbalização após o relato concorrente, sugerindo a reflexão do sujeito a partir da tarefa realizada (MATTOS et al, 2017).

Os testes que englobam o Protocolo Verbal são realizados em laboratório, em ambiente controlado pelos avaliadores. De forma geral, os participantes/usuários dos testes explicitam aquilo que estão pensando verbalmente conforme executam as tarefas propostas pelos avaliadores (PRATES; BARBOSA, 2003). Com o mínimo de interferência do próprio avaliador, a verbalização ou narração das tarefas é gravada e transcrita literalmente. Esses relatos verbais dos processos mentais conscientes dos usuários produzem o Protocolo Verbal.

Contudo, caso o usuário fique em silêncio por um longo período de tempo durante a execução do teste, cabe ao avaliador lembrar o participante de continuar narrando o que está pensando. A seguir, alguns exemplos das perguntas feitas aos usuários de modo a não influenciar os resultados finais dos testes: "O que você está pensando?" ou "O que você acabou de fazer?" (PRATES; BARBOSA, 2003). É importante que a interrupção não atrapalhe a atividade do participante, de outro modo, constitui-se uma desvantagem significativa em relação a outros métodos empíricos.

Para amenizar as desvantagens do método, é sugerido colocar dois participantes juntos durante a execução da tarefa. Assim, os usuários trocam diversas ideias entre si sobre o sistema: as dificuldades, os problemas, as soluções e atitudes relativos à atividade e à aplicação. Entretanto, a alteração das recomendações originais deste método pode progredir para um outro método conhecido por co-descoberta.

O Protocolo Verbal, além de ser um teste sem custos onerosos, também oferece ao avaliador a possibilidade de ter acesso a todos os processos do usuário. A técnica visa exatamente a análise de todo o processo de verbalização do participante enquanto realiza sua atividade. Assim, os avaliadores podem observar e compreender de forma mais eficiente os comportamentos, sentimentos e atitudes dos usuários em relação à atividade.

\subsection{Procedimentos Metodológicos}

A fim de realizar estudo de caso descritivo com uso de método de protocolo verbal explanado, delineia-se a seguir os procedimentos metodológicos utilizados. Vale ressaltar que dentre as técnicas do método utilizado, foi selecionada a verbalização do tipo concorrente para a pesquisa em questão.

De modo a alcançar os dados desejados e aplicação satisfatória do método apresentado, foi necessário garantir ambiente controlado, sendo os testes realizados no laboratório de informática, 
munidos de desktops, de uma Instituição de Ensino Superior, localizada na cidade de São Luís, Maranhão. O laboratório conta com 40 computadores fixos, climatização artificial, janelas e portas em vidro localizadas atrás dos usuários, além de quadro brando e Datashow.

Foram também utilizados como critérios para seleção dos participantes da pesquisa: o número de participantes, a ocupação, a idade e o grau de experiência com o portal.

Foram selecionados seis participantes, atendendo as recomendações de Nielsen (1994, apud CYBIS et al., 2010, p. 229) que afirma que para testes de usabilidade o número entre 06 e 12 é o suficiente, à medida que mais do que isso os dados acabam por se repetir. Todos os participantes são alunos do curso de Arquitetura e Urbanismo, pesquisadores de áreas afins aos temas abordados pelo portal, para garantir a compreensão e o interesse pelo conteúdo do portal. Os mesmos apresentam todos a mesma idade, 19 anos, tornando possível o controle da variável idade neste processo. Além disso, todos são usuários que nunca tiveram acesso ao portal anteriormente, de modo a tornar possível a identificação de experiências sem a influência de um processo de aprendizagem ou familiaridade antecessor.

Os mesmos foram selecionados de modo voluntário, tendo sido orientados a partir de Termo de Consentimento Livre e Esclarecido específico sobre o método de pesquisa, os objetivos e as questões éticas envolvidas. Não foram realizados registros fotográficos durante o experimento de modo a preservar a identidade dos usuários, além de diminuir o número de interferências externas à atividade realizada.

Os testes foram realizados com os usuários individualmente e, de modo a direcionar o uso do portal, foram estabelecidas cinco tarefas específicas para serem realizadas dentro do portal, considerando o proposto na ABNT ISO 9241-11, 2002, que afirma que para especificar ou medir a usabilidade é necessário identificar os objetivos para decompor a eficácia, eficiência e satisfação do usuário. As tarefas designadas foram:

Tabela 1 - Tarefas específicas do teste

\begin{tabular}{cr}
\hline Tarefa & Descrição \\
$\# 1$ & Compreender do que se trata o site, sendo capaz de demarcar seu objetivo e vínculo com \\
alguma instituição de ensino.
\end{tabular}

A partir da demarcação dessas tarefas, as mesmas foram apresentadas aos participantes separadamente para garantir a concentração em cada uma e verbalizações organizadas quanto a esta no momento de sua realização. Também, através dessa decisão é possível avaliar a capacidade de retenção de informação possibilitada pelo site, se ao realizar uma tarefa o usuário encontre outra, sem saber que a mesma será seu próximo desafio. 
A análise dos dados obtidos foi realizada seguindo as recomendações de Tullis \& Albert (2008), que afirma que a métrica mais significativa para análise de comportamento verbal é a razão entre comentários positivos, comentários neutros e comentários negativos. Tal método de análise traz poucos elementos para indicar recomendações específicas de redesign, mas trata-se de um método importante para identificação de portais que necessitam de atenção, bem como torna-se ferramenta ainda mais apurada à medida que é aplicada a cada nova proposta de interface para um site ou portal.

Segundo as recomendações de Tullis \& Albert (2008), para afinamento dos dados obtidos, comentários foram divididos em: fortemente positivos (01 - FP), outros comentários positivos (02 $\mathrm{OP}$ ), fortemente negativos (03 - FN), outros comentários negativos (04 - ON), sugestões de melhoria (05 - SM), questionamentos (06 - QU), variantes nas expectativas (07 - VE), confusão declarada ou falta de entendimento (08 - CD), e frustração declarada (09 - FD). A partir destes elementos discorreu-se a discussão dos dados obtidos.

\section{O Caso do Portal MOM}

O portal MOM - "Morar de outras maneiras" é caracterizado com um layout simples, podendo-se identificar duas áreas principais na tela: o menu lateral à direita com imagens simbolizando as opções disponíveis de navegação (área 02); e uma área central com dimensões maiores, contendo bastante opções de navegação demarcadas por imagens e textos associados, onde quase totalidade do conteúdo do portal é exibido (área 01). Na Figura 2 e Figura 3 é possível visualizar a página inicial do grupo MOM - "Morar de outras maneiras":

Figura 2 - Página Inicial do Portal MOM
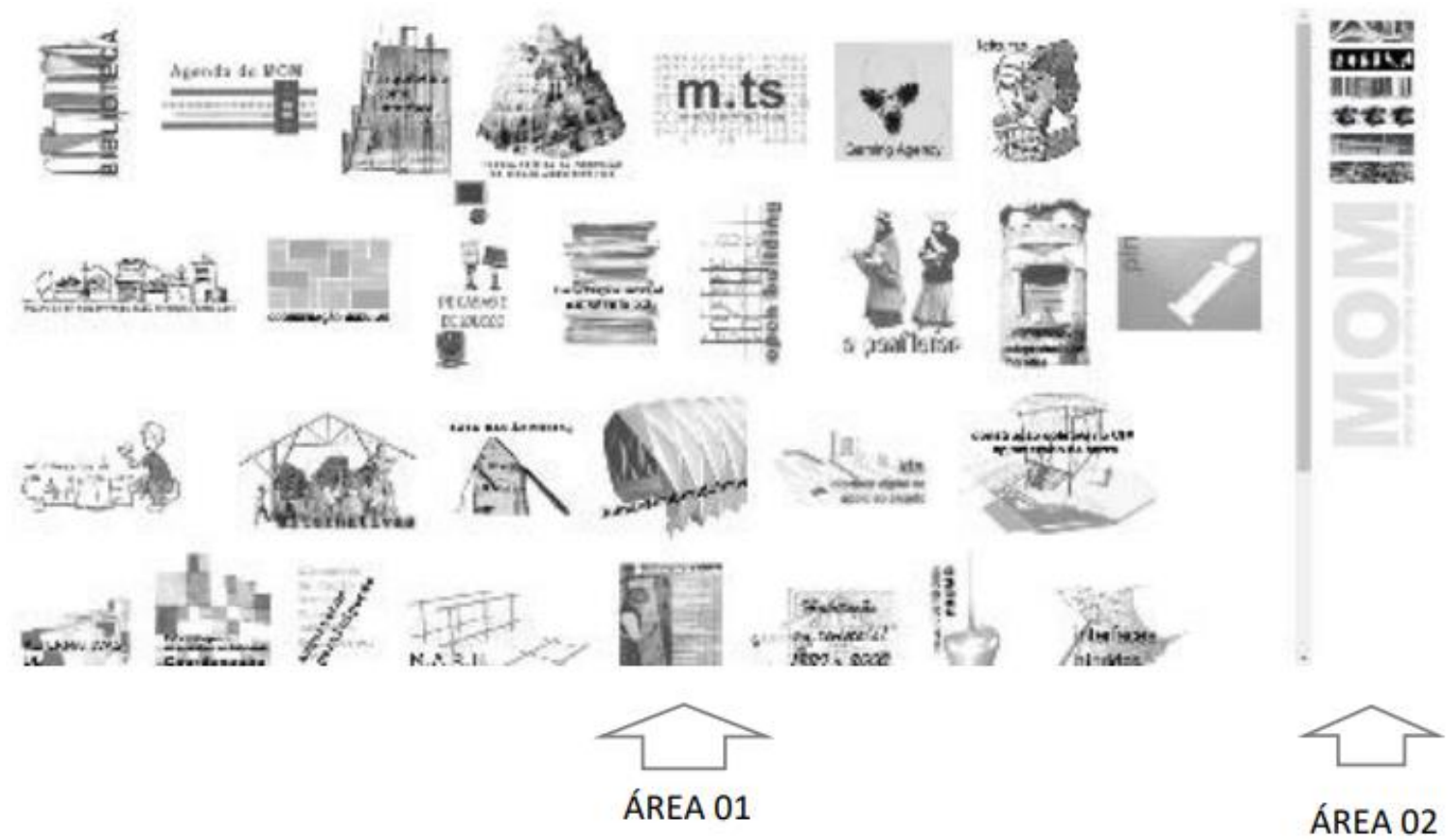

Fonte: http://www.mom.arq.ufmg.br/mom/index.html 
Apesar do portal apresentar uma paleta de cores monocromática em escalas de cinza, na área 01 à medida que o mouse sobrepõe alguma opção, a figura fica colorida e o elemento textual do referido item some.

Figura 3 - Imagem sem passagem do mouse / Imagem com passagem do mouse
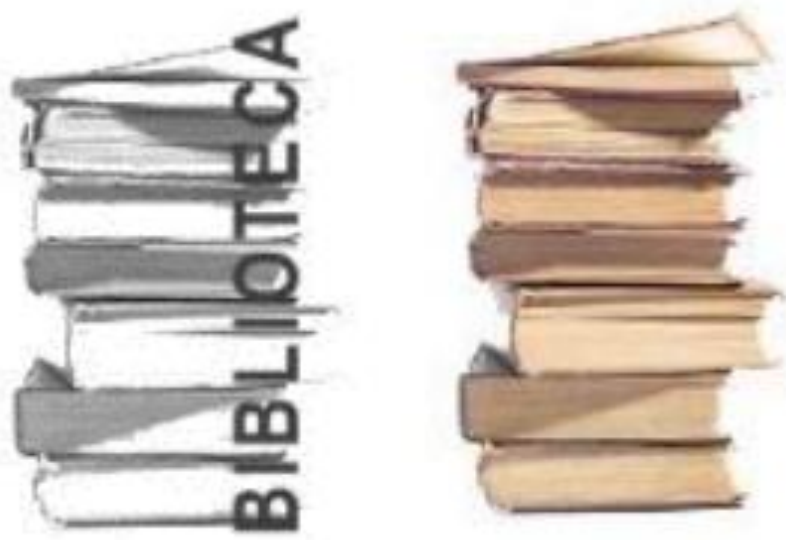

Fonte: Fonte: http://www.mom.arq.ufmg.br/mom/index.html

A área 01 é caracterizada por uma configuração de matriz, com os seguintes elementos clicáveis: Biblioteca, Agenda do MOM, Arquitetura como Interface, Teoria Crítica da Produção do Espaço Arquitetônico, Moradia e Tecnologia Social, Gaming Agency, Leituras, Práticas de Arquitetura para Demandas Populares, Coordenação Modular, De casas e de loucos, Habitação Social no Século XX, Open Building, A panfletar, Levantamento da Autoprodução de Moradias, "i", Instrumentos de Canteiros, Alternativas, Casa das Árvores, Oficina Estrutura Dobrável, IDA Interface Digital de Apoio ao Projeto, Construção coletiva do CIM Aglomerado da Serra, Alternativas de Adensamento; IV Colóquio de Pesquisas em Habitação - Coordenação Modular e Mutabilidade, Arquitetos e a Participação, M.A.R.H - Método de autoconstrução racional, Pesquisas em Habitação, Habitação em Revista(s) 1920 a 2000, Projeto de Pesquisa PRUMO, Interfaces Híbridas, II Colóquio Pesquisas em Habitação, MOM Debate, Interface de Espacialidade, Colóquio MOM / PAD / EMAU, MOM Debate e Entrevistas, totalizando 34 campos.

$\mathrm{Na}$ área 02 temos como elementos clicáveis: Apresentação, Equipe, Biblioteca, Contatos/Links, Atualizações, Pagina Inicial e MOM - Morar de outras Maneiras, totalizando 07 campos. Nesta área há uma configuração diferente dos ícones, que aparecem como configuração linear vertical, com imagens que quando ocorre a passagem do mouse se modificam para um elemento textual. A Figura 4 exemplifica tais variações, apresentando a nomenclatura Biblioteca como substituição ao ícone: 
Figura 4 - Imagem sem passagem do mouse / Imagem com passagem do mouse

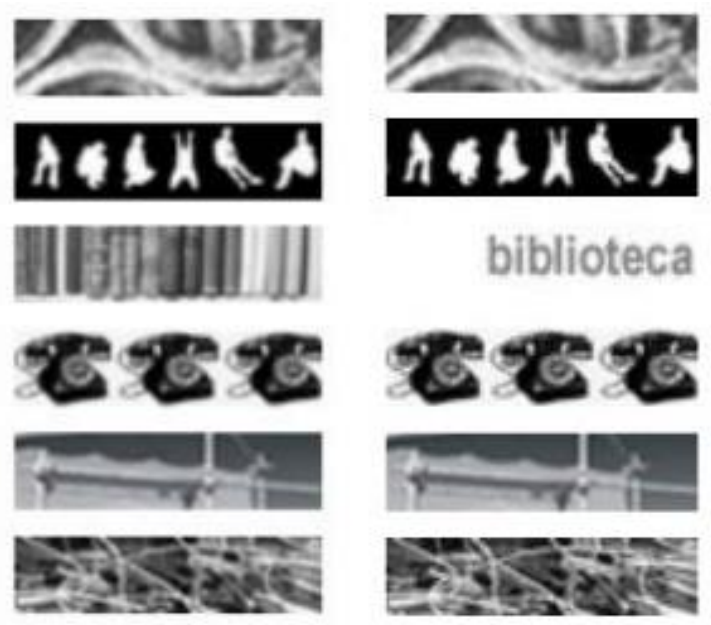

Fonte: Fonte: http://www.mom.arq.ufmg.br/mom/index.html

Desta maneira se observa que o layout do site não apresenta uma configuração usual, utilizando-se da criatividade para apresentar tarefas comuns em outros sites de grupos de pesquisa, tais como leituras recomendadas, pesquisas realizadas e eventos promovidos. Com os dados das verbalizações ocorridas durante o procedimento de teste pelos participantes da pesquisa, foram obtidos os dados apresentados na Tabela 2:

Tabela 2 - Dados verbais obtidos no discurso

\begin{tabular}{|c|c|c|c|}
\hline Classificação & Temas gerais & Exemplo do discurso & Total \\
\hline $01-\mathrm{FP}$ & Criatividade, Aspectos formais. & $\begin{array}{c}\text { Gente, que legal! Tão diferente, tão a cara do } \\
\text { grupo. Legal mesmo. }\end{array}$ & 01 \\
\hline $02-O P$ & Criatividade, Aspectos formais. & Criativo esse povo ein? (sic) & 07 \\
\hline $03-\mathrm{FN}$ & Aspectos formais, Orientação. & $\begin{array}{l}\text { Bem ruim esses desenhos né? Para um site de } \\
\text { arquitetos, achei bem mais ou menos. }\end{array}$ & 02 \\
\hline $04-\mathrm{ON}$ & $\begin{array}{l}\text { Aspectos formais, Orientação, } \\
\text { Estruturação. }\end{array}$ & Achei complicado e entender isso aqui. & 17 \\
\hline $05-\mathrm{SM}$ & Orientação, Estruturação. & $\begin{array}{c}\text { [...] gente, eles nunca ouviram falar de barra } \\
\text { de tarefas não? Isso aqui deveria está dividido. }\end{array}$ & 04 \\
\hline $06-Q U$ & - & - & 0 \\
\hline $07-V E$ & Aspectos formais. & $\begin{array}{l}\text { Nunca pensei que um site de uma universidade } \\
\text { tão conceituada fosse ser tão amador assim. }\end{array}$ & 01 \\
\hline $08-C D$ & Orientação. & $\begin{array}{l}\text { Não consigo entender nada aqui. Vocês } \\
\text { mexeram no site para dificultar mais? }\end{array}$ & 05 \\
\hline $09-F D$ & Orientação. & Impossível isso. Desisto. & 01 \\
\hline
\end{tabular}


Pode-se fazer a compilação destes dados, em comentários positivos, negativos e neutros, representados no gráfico da Figura 5:

Figura 5 - Gráfico com comentários positivos, negativos e neutros

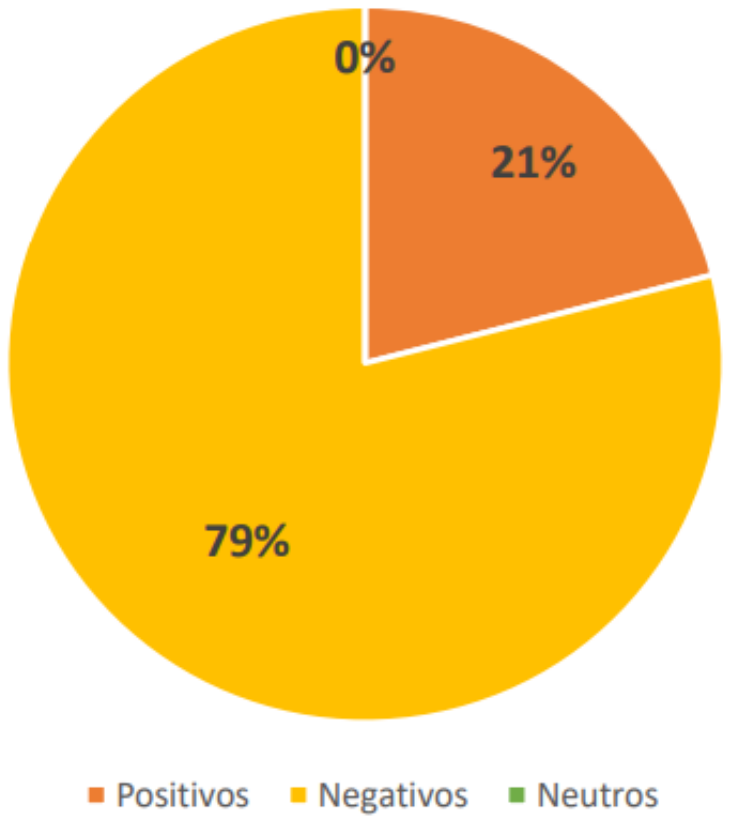

Além deste levantamento, é importante destacar que todas as tarefas solicitadas apresentaram dificuldades em serem concluídas. No entanto, apenas a "Tarefa 01: Compreender do que se trata o site, sendo capaz de demarcar seu objetivo e vínculo com alguma instituição de ensino", não foi possível ser concluída por três dos participantes.

\section{A Originalidade e a Usabilidade}

A análise do objeto de estudo deste artigo possibilita uma série de debates sobre o papel fundamental de um portal, isto é, seu atendimento às necessidades do usuário. Considerando que os usuários principais do referido site são indivíduos desvinculados do grupo de pesquisa e pertencentes a outra universidade, a quantidade de comentários negativos referentes a desorientação dentro do portal torna-se alarmante e demonstra uma inconsistência ao descumprir seu objetivo de uso e acesso facilitado. Como colocado por lida \& Guimarães (2016), usabilidade significa "facilidade e comodidade no uso de produtos, tanto no ambiente doméstico como no profissional. Assim, os produtos devem ser 'amigáveis', fáceis de entender, faces de operar e pouco sensíveis a erros".

É possível observar uma correlação clara entre este número de comentários negativos relativos a desorientação e a dificuldade por metade dos participantes da pesquisa em reconhecer de que se tratava o portal. Desse modo, o objetivo principal deste, ou seja, a divulgação da pesquisa realizada pelo grupo deixa de ser cumprindo logo no seu início, visto que se torna uma tarefa árdua caracterizar o próprio grupo dentro do site.

A questão da orientação dentro do portal pode ser analisada a partir dos pontos propostos por Kim e Hirtle (1995) de mapeamento cognitivo, onde propõem-se analisar: características do 
usuário / características da tarefa / características do ambiente. Logo observa-se em relação ao teste realizado, que os usuários apresentam vivência com sites de outras instituições que possuem o mesmo objetivo do referido, além da familiaridade com o assunto do site, ambos pontos definidos nos próprios critérios de seleção dos mesmos. É importante ressaltar que as tarefas selecionadas foram também escolhidas por tratar-se de informações corriqueiras a serem obtidas em sites de grupos de pesquisa.

No entanto, o maior ponto a se analisar aqui refere-se às características do ambiente virtual, na medida que Kim e Hirtle (1995) destacam que a complexidade de rota a ser seguida afeta a capacidade de orientação do usuário, ou seja, quanto maior a quantidade de pontos no processo de tomada de decisão, mais dificuldade terá o usuário de se orientar. Como foi destacado, o portal apresenta em sua página inicial 34 campos sem distinção formal ou de posição de importância, além de outros 7 campos laterais. Desta maneira, o site disponibiliza muitas opções para a tomada de decisão do usuário e, consequentemente, um impedimento para rápidas decisões.

Esta indistinção dos pontos também aparece como elemento de dificuldade de navegação ao considerarmos a noção de saliência, que Kim e Hirtle (1995) colocam como a saída da homogeneidade para possibilitar marcos no mapa cognitivo. Logo, a escolha de imagens distintas, no entanto homogeneizadas pela ausência de cor, pelo posicionamento e tamanho contribuem para desorientação do usuário.

Além do ponto acima citado, outro elemento destacado é o acesso visual ao alvo. Tal item no referido portal é comprometido pelas imagens escolhidas para representar cada link na área 01, seja em sua versão preto e branco, seja em sua versão colorida sem o texto. As imagens que servem como símbolos de navegação, prejudicam a inteligibilidade e algumas não são condizentes com os títulos/legendas a que se referem. Enquanto na área 02, a presença de apenas imagem ou texto quando a opção não é acionada pelo mouse - também prejudica uma visualização rápida e eficiente.

Outro ponto a ser destacado é a utilização de termos muito específicos ao grupo em questão. Estes termos apresentam uma difícil compreensão para usuários que não possuem domínio dos assuntos inerentes ao grupo de pesquisa. Como exemplo, destaca-se: Gaming Agency, Coordenação Modular, De casas e de loucos, A panfletar, "i", Instrumentos de Canteiros, Alternativas e Casa das Árvores. Todos estes são elementos dificultam o acesso visual ao alvo, logo tornam mais difícil a orientação por parte dos usuários.

O processo de desorientação no uso de um portal gera sentimentos negativos relativos ao mesmo, já que, como apontado por Hekkert (2006), a experiência do usuário nunca está apenas centrada em fatores físicos, mas operando sob alguns princípios gerais do prazer estético que incluem a unidade na variedade, ou seja, capacidade de detectar ordem no caos, organização da percepção e o efeito máximo por meios mínimos que estabelece a lógica de menor esforço para uso ou o caminho mais econômico, incluído o mínimo esforço físico e cognitivo. Desta forma, a compreensão do produto com poucos elementos de design opera como fator relevante para o prazer estético, e, portanto, elemento impactante no número de comentários negativos identificados.

Comparece como elemento de fundo em toda a argumentação apresentada a decisão formal dos desenvolvedores do portal de organizá-lo em matriz, com figuras específicas para assunto, sem a organização em cascata comum dos sites. Estes elementos, bem como as decisões mais específicas quanto a cor, o tipo de figura, a associação com texto ou não, apareceram como fatores relevantes 
para determinação da desorientação percebida pelos usuários no site.

Todavia, é importante observar que essas mesmas decisões, não usuais, são as causadoras dos comentários positivos acerca do mesmo. A sua originalidade e configuração formal diferenciada dos outros sites foi o que causou mais impactos positivos nos usuários.

Vale destacar que para análise destes dados é importante considerar o momento do teste em que essas verbalizações foram feitas, no início do processo, onde as tarefas ainda estavam em momento inicial, após o início das frustrações por desorientação tentando cumprir as tarefas estabelecidas, os comentários positivos diminuíram até cessar. Logo, observa-se que a impressão inicial do site foi marcada por mais comentários positivos do que negativos. Estes também compareceram nos momentos iniciais, mas em menor proporção. Após o início das tarefas os itens de orientação acabaram por minar os itens de ordem formal que despertaram relações positivas.

A partir do apresentado chega-se ao questionamento comum aos projetos de design em geral, e consequentemente ao design de interface: forma ou função, nesse caso representados por originalidade / criatividade ou usabilidade?

O caso em questão demonstra-se como exemplo claro da busca por uma apresentação formal criativa que fuja aos moldes padrões de outros portais, e, no entanto, por causa deste mesmo afã se perde no objetivo final do portal. Os mesmos elementos que foram apontados como originais e "a cara do grupo", são causadores dos processos de desorientação observados. Este elemento, somado à nomenclatura e imagens utilizadas para os links demonstram a distância no processo de criação do mesmo em relação ao usuário "real", ou seja, o usuário que não passou pelo seu processo de produção.

Desta forma, colocado por Moraes (2001, p. 15) como definição de usabilidade, "[...] adequação entre o produto e as tarefas a cujo desempenho ele se destina, da adequação com o usuário que o utilizará e da adequação ao contexto em que será usado", não é cumprido, ou sequer, levado em consideração, demonstrando a importância da inserção do usuário para elemento chave desde a concepção de qualquer interface.

\section{Considerações Finais}

O artigo realizou um aprofundamento teórico a fim de fundamentar a importância dos estudos focados no design de interface. Ao se apropriar do portal MOM - "Morar de outras maneiras" como estudo de caso que exemplifique um site acadêmico com prováveis dificuldades navegação pelos usuários, demonstra-se a ineficiência mesmo no meio acadêmico em projetar sites/portais com eficiência de uso.

Nota-se a relevância de estudos e aplicações práticas que visem a usabilidade em portais para satisfação dos usuários. Através do método de avaliação empírica denominado Protocolo Verbal, explanou-se de forma objetiva as principais dificuldades encontradas pelos usuários em relação ao site, bem como a necessidade de projetar interfaces sob a ótica do próprio usuário - isto é, design centrado no usuário.

Além disso, chegou-se a uma breve reflexão sobre a originalidade justaposta à usabilidade, considerando que ausência de um equilíbrio da mesma acarreta significativos impactos negativos aos usuários a longo prazo. Em contrapartida, quando utilizada de forma coerente, o portal aliado 
à originalidade pode proporcionar excelentes experiências ao usuário.

Os aspectos levantados para o referido site podem ser considerados na avaliação de outros sites de grupos de estudos acadêmicos, aumentando assim a capacidade de multiplicação do conhecimento proposta pelos mesmos. Tal análise pode ser feita também se utilizando outros métodos a fim de vencer as dificuldades de análise do comportamento do usuário apenas por sua capacidade de verbalização. Além de ser possível levantar dados acerca dos responsáveis pelo design destes sites, se profissionais realmente habilitados para tanto, ou apenas alunos ou professores do grupo de pesquisa, independente da formação ou objeto de estudo.

\section{Agradecimentos}

A apresentação deste artigo no evento foi financiada pelo edital Participação em apoio científico da FAPEMA (Fundação de Amparo à Pesquisa e Desenvolvimento Cientifico e Tecnológico do Maranhão).

\section{Referências}

BARANAUSKAS \& ROCHA, Maria C.C \& Heloisa V. Design e avaliação de interfaces humanocomputador, 2 ed. Campinas:NIED/UNICAMP, 2003.

BITTENCOUT, F. R.; DIAS, S. M. P. Percepção dos docentes e discentes do ensino superior acerca da utilização de um portal acadêmico. In: Convibra Administração - Congresso Virtual Brasileiro de Administração, 8, 2011. Anais online... CONVIBRA, 2011.

CYBIS, Walter et al; Ergonomia e usabilidade: conhecimentos, métodos e aplicações. São Paulo: Novatec, 2007.

FONSECA, Jansley N. Conhecendo a engenharia de usabilidade. Trabalho de Conclusão de Curso, Faculdade Integrada do Ceará, Fortaleza, CE, 2004.

FUJITA, MSL., org., et al. A indexação de livros: a percepção de catalogadores e usuários de bibliotecas universitárias. Um estudo de observação do contexto sociocognitivo com protocolos verbais [online]. São Paulo: Editora UNESP; São Paulo: Cultura Acadêmica, 2009.

HEKKERT, Paul. Design aesthetics: principles of pleasure in design. In: Psychology Science, Volume 48, p. $157-172,2006$.

IIDA, Itiro; GUIMARÃES, Lia Buarque de Macedo. Ergonomia: Projeto e Produção. 3a ed. São Paulo: Edgard Blücher, 2016.

KIM, H., \& HIRTLE, S. C. Spatial metaphors and disorientation in hypertext browsing. In: Behaviour \& Information Technology, n. 14, p. 239- 250, 1995.

LOWDERMILK, T. Design Centrado no Usuário: um guia para o desenvolvimento de aplicativos amigáveis. São Paulo: Novatec Editora, 2013.

MATTOS, T. C. L.; NEVES, D. A. B.; REDÍGOLO, F. M.; FUJITA, M. S. L. Protocolo Verbal: verbalizações concorrente e retrospectiva. Revista Ibero-Americana de Ciência da Informação, v. 10, p. 49-66, 
2017.

MEMORIA, F. ; MONT'ALVÃO, C. R. . Pesquisas em Usabilidade no Brasil: Academia x Mercado. In: 3o. USIHC - 3o. Congresso Internacional de Ergonomia e Usabilidade, Design de Interfaces e Interação Humano-Computador, 2004, Rio de Janeiro, RJ. Anais 3o. USIHC. Rio de Janeiro, RJ: LEUI/PUC-Rio, 2004.

MORAES, D. O concreto e o virtual: mídia, cultura e tecnologia. Rio de Janeiro: DP\&A, 2001.

MORE, J. D. et al. Avaliação da eficiência do portal Globo.com: um estudo de caso à luz da teoria dos conjuntos Fuzzy. In: JISTEM - Journal of Information Systems and Technology Management, v. 7, n. 2, São Paulo: 2010.

NIELSEN, J. Usability 101: Introduction to Usability. 2012. Disponível em: . Acesso em 29 jul. 2013

PRATES, R.; BARBOSA, S. Avaliação de Interfaces de Usuário: Conceitos e Métodos. In: Anais Do XXIII Congresso Nacional Da Sociedade Brasileira de Computação, 1-4, 2003. Disponível em: http://homepages.dcc.ufmg.br/ rprates/ge_vis/cap6_vfinal.pdf. Acesso em 20 de nov. de 2017.

SILVA, F. S.; SERAFIM, M. L. Redes sociais no processo de ensino e aprendizagem: com a palavra o adolescente. In: SOUSA, RP., et al., orgs. Teorias e práticas em tecnologias educacionais [online]. Campina Grande: EDUEPB, p. 67-98, 2016.

TULLIS, T; ALBERT, W. Measuring The User Experience: collecting, analyzing, and presenting usability metrics. Morgan Kaufmann, 2008. 